\title{
The benefits of exposing post-secondary students to entrepreneurship training in Trinidad and Tobago
}

\author{
Abede Jawara Mack ${ }^{1 凶}$, Daniel White ${ }^{1} \&$ Osiris Senghor ${ }^{1}$
}

Technical Vocational Education and Training (TVET) serves as a pillar for economic stability globally. Entrepreneurship education provides young people with essential skills that can be used in a positive manner, thus enabling them to be employers rather than employees. Marrying TVET and entrepreneurship education can help Trinidad and Tobago (T\&T) in tremendous ways. These two subjects TVET and entrepreneurship can lift T\&T to global prestige. Given this context, the study explored the benefits of exposing Post-Secondary TVET students to entrepreneurial training. An investigation was carried out using a mixmethods approach. The use of regression analysis and Spearman's Correlation Analysis were used that determine the relationship between exposing Post-Secondary Technical Vocational Education and Training Students (PSTVETS) to entrepreneurship education and their interest in entrepreneurial training. Additionally, qualitative data was incorporated by utilising content analysis, focus groups and semi-structured interviews. The data revealed there was an absence of entrepreneurship education. Upon further investigation there was no real entrepreneurship culture or framework implemented within the PS schools. The results also showed the more students are exposed to entrepreneurship education more they are inclined to pursue entrepreneurship endeavours. Data also allowed the reader to grasped copious challenges experienced within TVET in T\&T, that impacts on entrepreneurial training within post-secondary institutions in T\&T. The researchers put forward an entrepreneurship education model that can be incorporated in the training of post-secondary schools. Additionally a strategy was articulated as to how entrepreneurship education can be adopted within the training of post-secondary institutions. Providing an adequate framework for entrepreneurial training within entrepreneurship education, and TVET provides originality and contribution to the field of TVET and entrepreneurship education.

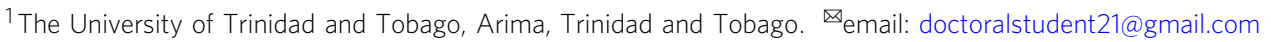




\section{Introduction}

his study allowed the researchers to put forward an original contribution to the field of Technical Vocational and Training (TVET) and entrepreneurship education. The authors provided meaningful insights and ideas that will contribute positively to a greater body of knowledge within the field of TVET and entrepreneurship education, especially within the field of Small Islands Developing States (SIDS). TVET plays an important role in the transformation of economies by its social and economic benefits. According to Mack and White (2019) the idyllic education platform for socio and economic benefit is TVET. TVET serves an important role in the development of any society. The benefits of TVET are enormous and is something policy makers along with governments should look at. There is a momentum that TVET provides that is geared towards the advancement of young people. TVET is an option where income can be generated that aid with the difficulties of unemployment (Mack et al., 2019). TVET is expounded upon as a critical pillar in any country's development plan. Mends-Brew and Dadzie (2016) shared a valuable opinion about TVET, by stating TVET is a crucial sector that supplies the indispensable technical and professional human resources capital in ample amounts required for national growth in a sustainable manner. TVET has played an instrumental factor in United Nations Educational Scientific and Cultural Organization (UNESCO) mandate for education (Tikly, n.d). Although the World bank and UNESCO have varying views on investing in TVET, general they provide rationales for its investment (Tinkly, 2013).

This study looks at the role exposing post-secondary TVET students (PSTVETS) to entrepreneurship education and how this exposure can impact their interest towards entrepreneurship pursuits. Placing focus on TVET is extremely important Aring (2011) provided literature on the impact of unemployment within the 15-29 age group. The author shared quite eloquently on the benefits on placing emphasis on TVET, which can help in eradicating unemployment with the 15-29 age group, in a significant way. Consequently, the intention of the writers is to examine how acquainting PSTVETS in entrepreneurship education will influence their interest in pursuing entrepreneurial paths. Also, the rationale is to put forward an entrepreneurship model that can influence the benefits of TVET and entrepreneurship education methods in the future for the nation of T\&T.

Given the revelations expressed thus far it allows the reader to grasp the relevance and vital role TVET can play in the transformation of economies and societies. Highlighting the transformative role TVET can play will contextualise the significant ideologies of this research piece.

The research looks at four (4) post-secondary TVET institutions (PSTVETI) within T\&T. The institutions are spread throughout T\&T. PSTVETI 1, offers training in several programme offerings, some of the courses included are: Welding, Plumbing, Engineering programmes in Mechanical, Electrical/ Electronic and Mechatronics, Engineer-In-Training,. They also conduct other expert and personalised training programmes. This school offers a self-development programme called Life Skills Training that aims to cover entrepreneurship in a topic in the life skills curriculum, which is a minute aspect of a wider module Employment \& Financial Management Skills.

PSTVETI 2, trained over twelve thousand $(12,000)$ craftsmen and over 120,000 persons in Information and Communications Technology. They pursue TVET programmes in: Heavy Equipment Operator, Electrical Installation, Automotive Services, Welding, Instrumentation, Plumbing, Masonry, Machine Shop among many other courses. The school was organised to link; industry, government, and world-wide institutions. The intention was for the institution to a be self-sufficient. They also offer a selfdevelopment programme called Life Skills Training that aims to cover entrepreneurship in a topic in the life skills curriculum, which is a minute aspect of a wider module Employment \& Financial Management Skills.

PSTVETI 3 teaches courses at the Associate degree level. Short courses are also administered to train students in industry standards. The school train students in: Culinary Management, Food and Beverage, Baking and Pastry Arts, Hospitality Operations, Hospitality Management. The school have facilities that are used to train students to meet professional standards that are in keeping with industry benchmarks. Currently, the institution offers entrepreneurship education as a within their various hospitality programmes.

PSTVETI 4, offer an entrepreneurship education course that runs for 144 contact hours, however it is optional. The school has grown to be an option for TVET students to pursue several courses. Students mainly come from unemployed youth, retrenched employees, and displaced citizens between 15 and 60 years. Training is offered for full-time, part-time and as communitybased projects. Students are exposed in: Cosmetology, Tour guiding, Plumbing, Welding, Carpentry, Electrical, among many courses. This institution provides training country

\section{Literature review}

Entrepreneurship is a vital economic driver in any country. It plays a crucial role its development of any nation. A powerful confession was put forward by (Dhaliwal, 2016) where the author stated that development of a country lies in entrepreneurship. One of the most critical contributions to development of the country's economy is entrepreneurship. The government of Nigeria addressed youth unemployment and exclusion of the youth population via entrepreneurship (McCallum, 2019). The input of entrepreneurship is a significant player in advancing countries agendas, especially in the lines of economic prosperity. When there is decisive intervention by an educator to influence learners by assisting them with skills through by entrepreneurial qualities, this helps with survival competencies (Gamede, 2017).

Theoretical Model-Theory of planned behaviour (TPB). Abioye (2020) explained the notion on how intentions are developed into action. The intend of this study is to explore the entrepreneurial aims of PSTVETS. Ajzen (1991), stated that the TPB model provides an opportunity to harness ground breaking research, which allows for clarity in the entrepreneurial plans. The writers intend to understand the schemes that are in place in training students to become business owners. Liñán et al. (2011) and Liñán and Santos (2007) provided insight on the subject of entrepreneurship intentions, by highlight the theoretical model of TPB by Ajzen (1991), the authors saw the TPB model as a framework that defines how the cultural and social environments impact human behaviour. The utterances put forward by the scholars, provides the researchers with a model to ascertain the entrepreneurial intentions of students against the plans for entrepreneurship by the PSTVETI. It also allows the authors to understand the present environment and how it can influence students to adopt entrepreneurship as a career path.

Gamede (2017) stated that entrepreneurship is a dynamic mechanism to spur economic growth. The author further, argued there exist a positive correlation between creating a business and entrepreneurship education. These revelations highlight the significance entrepreneurship education plays in the development of any country. There has been strides by the T\&T's government 
to cultivate the small business sector in T\&T in a systematic and deliberate manner (Ramkissoon-Babwah, 2012). These approaches were done with the anticipation of facilitating employment growth through entrepreneurship (RamkissoonBabwah, 2012).

Seng (2010) articulated a profound point on Singapore's education system, stating that administrators needed to address the needs of Singaporeans that fall under 25\% within their performance at school and who were less academically inclined. Singapore formed the Institute of Technical Education (ITE) to generate alternate pathways, and diversity to the robustness of the Singapore education system. This brought tremendous benefits and success to their educational system. Additionally, the government of Singapore saw the need to turn things around for their economy to grow. They focused on providing the country with an economic plan to chart the way forward for Singapore's development and they adopted TVET as a business model for this to become a reality. Incorporating entrepreneurship education is of necessity moving forward. Skills/competencies-based education and training, which would facilitate the advancement of entrepreneurship and business creation within T\&T (Ramkissoon-Babwah, 2012).

According to Tambunan (2019) studies has shown the value of micro, small and medium enterprise, especially since it provides an opportunity for persons to be employers and the advantages it provides within economic and social advancements.

Mack et al. (2019), outlined the value and benefits entrepreneurship education can play within TVET institutions in T\&T, not to mention the authors articulate ideas on the significance of incorporating entrepreneurship education, which can lead to economic and social advancements. The study set outs to evaluate the role entrepreneurship education can play in exposing TVET students to entrepreneurship and determine how this influence their interest in entrepreneurship pursuits.

\section{Methodology}

\section{Purpose of the study}

Hypothesis. $\mathrm{H}_{1}$ : A relationship exists between exposing students to entrepreneurial training and students' attraction towards entrepreneurship endeavours

$\mathrm{H}_{0}$ : No relationship exists between exposing students to entrepreneurial training and students' attraction towards entrepreneurship endeavours

\section{Research questions.}

1. What is the present environment involving entrepreneurship education practices at TVET institutions?

2. How does entrepreneurship education or the lack thereof affect students pursuing entrepreneurial paths?

3. How is the current curriculum of TVET skills training equipping students to prepare for entrepreneurship?

4. How can incorporating an entrepreneurship education model improve TVET in T\&T?

Data collection. According to Brannen (2005), using the mixedmethod allows the study to incorporate more than one type of research method. The author stated that this is done by using a mixture of quantitative and qualitative methods. Saunders et al. (2003) explained that triangulation refers to utilising diverse data collection methods within a single study to ensure that the data informs the researcher what needs to be told. Thus, the researchers would have adopted a mixed-method tactic within this study, which was employed by a triangulation approach that included a survey (questionnaires), interviews and focus groups and content analysis. Adopting these three choices in collecting data, allowed the researchers to ascertain the exposure of entrepreneurship education within the four PSTVETI, answer the research hypothesis and research questions. The researchers used three methods to collect data, which is explained further below. Additionally, the authors captured data from; students, teachers, and administrators, this was done to obtain a wide perspective of entrepreneurship education within the four PSTVETI. It allowed the researchers to determine if students are being exposed to entrepreneurship education within the schools in question.

Survey. When using the survey the research utilised a questionnaire to capture data from the student population within the four PSTVETI. The population comprised of 7176 students in total. From that grouping the authors sort to captured data from 600 participants, which 446 were obtained from the survey, this represented a $74.33 \%$ response rate. Based on Singh and Masuku (2014) recommendation, for a population size between 7000 to 9000 , a sample size of 383 is acceptable for a precision level $\pm 5 \%$ and a $95 \%$ confidence level and $p=0.5$. The authors adopted a $5 \%$ margin of error and a 95\% confidence level. According to Singh and Masuku (2014), a 95\% confidence level with a 5\% margin of error means that 95 out of 100 samples will reflect the population's accurate value. Additionally, Boxhill et al. (1997), highlighted cluster sampling occurs when it is difficult or unlikely to obtain an exhaustive list of participants from a population. The study focused on four PSTVETI spread throughout Trinidad and Tobago, which is a nationwide focus. It would not have been easy to draw a list of participants from every institution; hence using this approach was beneficial to the researchers. It provided advantages and an excellent methodological approach to gather data that informed the study positively. The researchers were able to administer the questionnaires to the students at the institutions through face-to-face interaction. Students were given the questionnaires, and the researchers retrieved them as soon as they were finished. Most questionnaires were completed in under $10 \mathrm{~min}$; however, some students required more time.

Content analysis. Content analysis is a qualitative approach to collecting data, which was adopted by the researchers for this study. Bowen (2009) highlighted that content analysis is an oftenused method that validates and bolsters research. The researchers were able to gather data that involve insights related to the schools' curricula, by communicating to the various personnel responsible for implementing the curricula (instructors, curriculum officer and administrators) within the schools. Data emerged from: informal discussions, phone calls, emails, and WhatsApp messages. Content analysis is seen as an uninstructive method in gathering data. This approach was utilised to harness information relating how entrepreneurship education is taught at the four PSTVETS.

Interviews. Twenty-five (25) interviews that included focus groups were carried out in a face-to-face manner, which involved staff from the four (4) TVET institutions and the Executive Officer from TVET's regulatory body. The study adopted a structed protocol for all interviews (25), which were taped and transcribed verbatim. The interview sessions lasted $\sim 30 \mathrm{~min}$., which allowed the interviewees to substantiate information generated during the interview meetings.

In interviews, when the researcher begins to hear the same comments again and again, data saturation is being reached... It is then time to stop collecting information and to start analysing what has been collected (Saunders et al., 2018) 
Reaching data saturation allowed the researchers, to stop the data gathering after the 25 interviews and move forward with the research.

Saunders et al. (2003) explained that the utilisation of interviews could help the researcher gather cogent and dependable data pertinent to the research questions and objectives. This was indispensable to this study since addressing issues involving entrepreneurship education and TVET within T\&T meant answering many questions. In Table 1 (above), the interviews and focus groups were conducted in a semi-structured format. The researchers had a list of guided questions to steer the interview process. This research method was insightful as the researchers were able to generate a wealth of data that provided deep understandings and revelations involving TVET and entrepreneurship education within the TVET institutions. The data answered many questions and provided a significant amount of invaluable research involving TVET and entrepreneurship education within T\&T. Also, in the focus groups, the interviewees responded to the questions posed to them and provided great details in most cases. The instructors responded by expounding and affirming what the others said. The researcher conducted one-on-one interviews with the administrators from TVET institutions, which provided an opportunity for interaction and answers to the many questions.

The authors adopted purposeful sampling mainly due to its usefulness within qualitative research. According to Patton (2015), purposeful sampling provides a rational and powerful basis to this method of sampling, mainly because it allows the researcher to gather data, by selecting information-rich cases for exhaustive study. The author's argument was this method provides an opportunity to learn about the disputes of central importance to the purpose of the enquiry. This was the rationale for pursing this approach within this study.

\section{Data analysis}

Survey. The survey data was analysed using the software Statistical Package for the Social Sciences (SPSS). The questionnaire/ survey included: Likert-type scale questions, Rating scale questions, Multiple choice questions, Semantic differential scale questions. Four areas were concentrated upon for data which included: Demographics, Students' interest in entrepreneurship, The TVET institutions' ability to prepare graduates to become entrepreneurs, Evaluating the systems in place to support entrepreneurship endeavours. The students (446) from PSTVETI were asked to specify their level of agreement with the questions by placing a tick in the suitable location on a 5 point Likert-type scale to ratio question or closed-ended questions. With 1 representing strong disagreement and 5 representing strong agreement. The researchers administered the survey by hand, and students were asked to state their views on entrepreneurship education at the PSTVETI. The researchers also carried out a pilot study, which allowed them to improve the instrument, before it was formally distributed. Internal reliability was measured for exposure (14 items) used in the Likert scale and the rating scale. The result was 0.739 , hence representing a satisfactory level of internal consistency for the items used in the scale.

Content analysis. This data assisted the authors in gaining insights and obtaining information on the schools' curricula. Each TVET institution shared information about the various courses offered. According to Bowen (2009), content analysis is a method of research that is qualitative in nature. In this method of research, it allowed the researchers to interpret the documents, which gave the research meaning, providing an assessment of the presence of entrepreneurship education within the

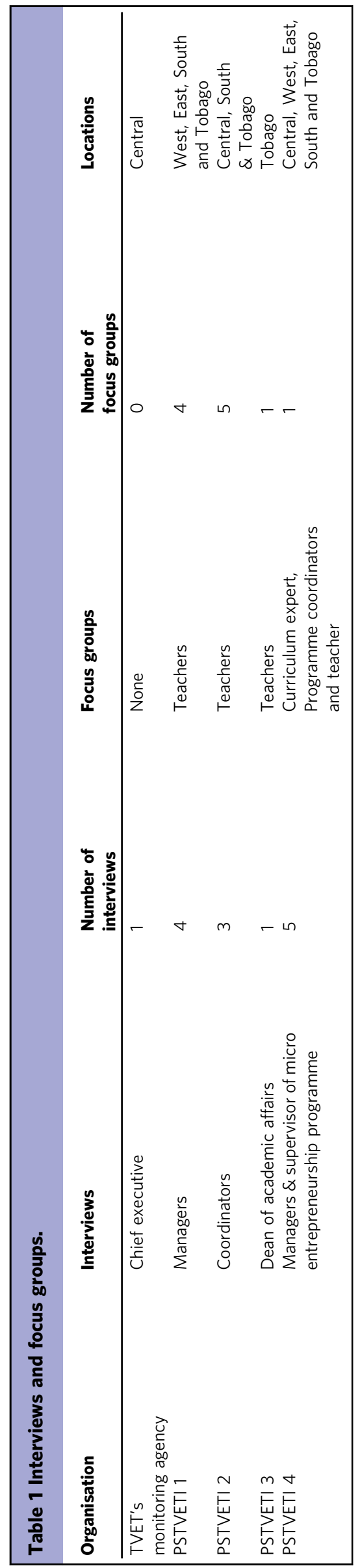


four PSTVETI. The researchers set out to explore entrepreneurship education in the PSTVETI. Pursuing this approach allowed the investigators to answer the third research question which states: How is the current curriculum of TVET skills training equipping students to prepare for entrepreneurship?

Interviews. The interviews were analysed using a thematic analysis. Bryman (2012) pointed out that thematic analysis is a standard method used in analysing qualitative data. Ryan and Bernard (2003) (as cited in Bryman, 2012) mentioned that themes usually incorporate repetitions or recurring topics in the data. The researcher included this method in analysing qualitative data for its flexibility and popularity. This method provided deep insights and an excellent platform for interpreting trends and issues gathered from the research. The author adopted this approach in the study to analyse data qualitatively to acquire the necessary results needed while following best practices. The interviews allowed the researchers to ascertain the obstacles facing the implementation of entrepreneurship education within PSTVETI, also it provide answers to the research questions.

\section{Findings}

More exposure to entrepreneurship training leads to interest in becoming a business owner. A logistic regression analysis was conducted to predict causes TVET students' entrepreneurship

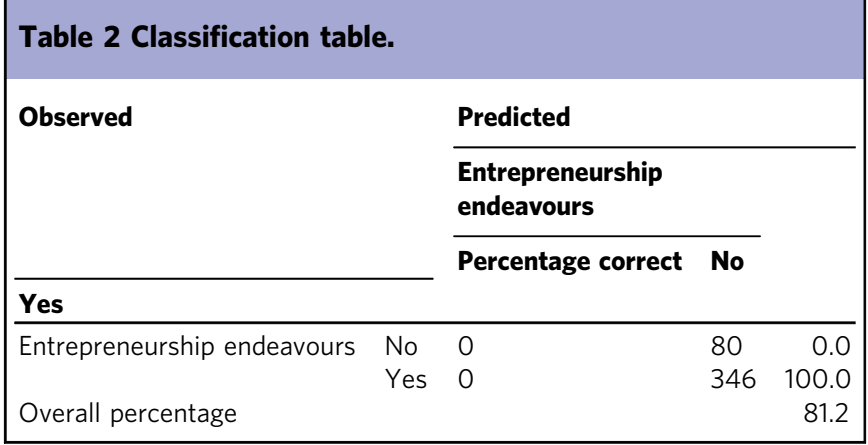

endeavours (dependent variable), for 446 TVET students, using exposure to entrepreneurial training, A test of the full model against a constant only model was statistically significant, indicating that the predictor variables as a set, reliably distinguished between those who indicated interest in pursuing entrepreneurship and those who indicated no interest in pursuing entrepreneurship (chi square $=9.887, p=0.042$ with $\mathrm{df}=4$ ). That is, the model successfully predicted $81.2 \%$ of the cases (which was highlighted in Table 2 below).

Also, the Hosmer and Lemeshow statistic is $>0.05$, which means that the null hypothesis of no difference between the observed and predicted models is rejected. Therefore, the alternative hypothesis is accepted, which state that there is a difference between the observed and predicted models. That is, the $\mathrm{H}-\mathrm{L}$ has a statistic of 0.362 is not statistically significant, which means that the model's estimates fit the data at an acceptable level.

The Wald statistic indicates the significance of each predictor. In this regression analysis, the Wald criterion demonstrated level of exposure to entrepreneurship training $(p=0.005)$, made a significant contribution to the prediction where $p<0.05$. Therefore, the level of exposure TVET students have to entrepreneurship training at their schools has an influence on their desire or interest in pursuing the development of their own business, as these two variables showed statistical significance in the analysis.

For this study, the hypothesis was tested using Spearman's correlation coefficient (rho). This allowed the researchers to ascertain the existence of any correlations, the direction of correlations and at what level of significance the null hypotheses are rejected in favour of the alternative hypotheses or accepted in the absence of significance (Tables 3 and 4).

Table 5 showed the results of a Spearman's correlation for the sample indicated that the level of exposure to entrepreneurship training was significantly associated with interest in entrepreneurship (rho $=0.132, N=439, p=0.006$, two-tailed). Therefore, the results show that the null hypothesis is rejected in favour of the alternative. Therefore, there is a positive relationship between TVET students' level of exposure to entrepreneurship training and interest in owning their own business. Therefore, the greater

Table 3 Showing variables in the equation.

\begin{tabular}{|c|c|c|c|c|c|c|c|c|}
\hline \multirow[t]{2}{*}{ Variables } & \multirow[t]{2}{*}{ B } & \multirow{2}{*}{ S.E. } & \multirow[t]{2}{*}{ Wald } & \multirow[t]{2}{*}{ df } & \multirow[t]{2}{*}{ Sig. } & \multirow[t]{2}{*}{$\operatorname{Exp}(B)$} & \multicolumn{2}{|c|}{ 95\% C.I. for EXP(B) } \\
\hline & & & & & & & Lower & Upper \\
\hline Exposure to entrepreneurial training & 0.024 & 0.009 & 7.907 & 1 & $\begin{array}{l}0.005 \\
0.825\end{array}$ & 1.025 & 1.007 & 1.042 \\
\hline
\end{tabular}

Table 4 Spearman's correlation analysis.

\begin{tabular}{|c|c|c|c|}
\hline Variables & Coefficients & Entrepreneurship endeavours & Exposure to entrepreneurial training \\
\hline \multirow[t]{3}{*}{ Entrepreneurship endeavours } & Correlation coefficient & 1.000 & $0.132^{\star \star}$ \\
\hline & Sig. (two-tailed) & 0.01 & 0.006 \\
\hline & $N$ & 442 & 439 \\
\hline \multirow[t]{9}{*}{ Exposure to entrepreneurial training } & Correlation coefficient & $0.132^{\star \star}$ & 1.000 \\
\hline & Sig. (two-tailed) & 0.006 & 0.01 \\
\hline & $N$ & 439 & 442 \\
\hline & Sig. (two-tailed) & 0.303 & 0.01 \\
\hline & $N$ & 428 & 432 \\
\hline & Sig. (two-tailed) & 0.210 & 0.169 \\
\hline & $N$ & 442 & 442 \\
\hline & Sig. (two-tailed) & 0.396 & 0.384 \\
\hline & $N$ & 441 & 442 \\
\hline
\end{tabular}


Table 5 Showing relationship between student interest in pursuing entrepreneurship and exposure to business training.

\begin{tabular}{llll} 
Variables & Coefficients & Entrepreneurship endeavours & Exposure to entrepreneurial training \\
\hline Entrepreneurship endeavours & Correlation coefficient & 1.000 & $0.132^{\mathrm{a}}$ \\
& Sig. (two-tailed) & - & 0.006 \\
& $N$ & 442 & 439 \\
Exposure to entrepreneurial training & Correlation coefficient & $0.132^{* \star}$ & 1.000 \\
& Sig. (two-tailed) & 0.006 & - \\
& $N$ & 439 & 442 \\
\hline
\end{tabular}

Table 6 Cronbach alpha analysis showing level of exposure.

\section{Reliability statistics}

Cronbach's Alpha

0.937

$\mathbf{N}$ of Items

14

Table 7 Curriculum of TVET schools.

\begin{tabular}{llll}
$\begin{array}{l}\text { TVET } \\
\text { institution }\end{array}$ & $\begin{array}{l}\text { Accounting, Customer Care, } \\
\text { Economics, Entrepreneurship, } \\
\text { Marketing and Management }\end{array}$ & $\begin{array}{l}\text { Technical } \\
\text { subjects }\end{array}$ & $\begin{array}{l}\text { Structured } \\
\text { teaching }\end{array}$ \\
\hline PSTVETI 1 & X & $\sqrt{ }$ & X \\
PSTVETI 2 & X & $\sqrt{ }$ & $X$ \\
PSTVETI 3 & $\sqrt{ }$ & $\sqrt{ }$ & $\sqrt{ }$ \\
PSTVETI 4 & $\sqrt{ }$ & $\sqrt{ }$ & $X$ \\
\hline
\end{tabular}

the level of exposure to entrepreneurship, is the more TVET students reporting interest in pursuing entrepreneurship/owning their own business.

Cronbach analysis. The Cronbach alpha analysis indicated that Level of Exposure (0.937) measured using fourteen items was acceptable and therefore these fourteen questions did reliably measure the item (Table 6).

An absence of entrepreneurship education within PSTVETS. Table 7 (above) provides the reader with the various subjects/ courses offered at PSTVETI. It highlights the content and what is being taught at the institutions. It also gives a snapshot of which institutions are pursuing entrepreneurship education, which two (2) of the schools pursue entrepreneurship education and two (2) of the schools do not. The data emerged from the content analysis (qualitative data) data showed, there were some focus on business subjects, additionally, two schools allowed students to select entrepreneurship courses, but they were not mandatory. PSTVETI 3 and 4 had no entrepreneurship courses. Thus, one can see the absence of entrepreneurship education within the four PSTVETI. All schools had focus on technical subjects., however, little emphasis was placed on harnessing the entrepreneurial culture within PSTVETI. The study also featured interviews, inclusive of focus groups. When instructors/administrators were asked about entrepreneurial training the responses were not positive.

Please see response below:

Question: "How is entrepreneurship education implemented at your school, in terms of the type of courses administered, who teaches the programme, and how it is taught?

Responses:
Educator response: "The only aspect of entrepreneurial studies that I know that are part of these programs it's a little bit in communications where they teach them where they could access some money, but it's not in depth to show them how to do a business plan, how to approach a financial institution with a proposal saying this is what I want and this is what I could do that does not happen."

Educator response: "I advise my students when they have finished the program to at least spend a year of two getting some hands-on experience"

Educator response: "We try to open the trainee's eyes, but that is informal, and you can't measure that because whenever we feel like it we talk about it."

Educator's response: "It's non-existent."

Climate of PSTVETI. The qualitative data showed the present environment surrounding TVET within the mentioned institutions, leaves a lot to be desired. There is an absence of adequate systems and mechanisms to incorporate or facilitate entrepreneurship training from taking place within PSTVETI. The data allows the reader to grasp the details involving the present climate and how it provides answers to the research question (number 1, mentioned below). The data shows there are several hurdles engulfing TVET within T\&T. Themes emerge in two sets of data: hurdles and resources. The data provides insight into the factors that can contribute to an absence of entrepreneurship education practices within the PSTVETI.

Theme one (hurdles), data emerged from the thematic analysis showing various themes, which are listed below:

1. Attrition

2. An absence of industrial training

3. No regulatory functions in PSTVETS

4. Leadership issues in PSTVETS

5. Poorly structured teaching/lack of entrepreneurial training

6. Stigma

7. Poor quality of trainees

Data from theme two (resources), emerging from the thematic analysis showing various themes, which are listed below:

1. Capital

2. Machinery and materials

3. Physical infrastructure

The data emanating from both themes hurdles and resources, highlights the challenges students and institutions are faced with. The problems are compounded, not having the required resources along with various obstacles puts the PSTVETS in a disadvantageous position.

\section{Discussion}

Entrepreneurship is a major tool in assisting a country with social challenges. Based on the revelations articulated so far, TVET and entrepreneurship education are important challenges that can be 
used for T\&T’s development. Additionally, TVET and entrepreneurship education can be used as a platform for young people to engage in training, which would benefit them. These ideas should be explored moving forward. TVET is known, the world over to help in the eradication of poverty and social ills. Entrepreneurship education is known globally as a pillar in economic transformation. This research looked at exposure to entrepreneurship education and the impact it can have on influencing PSTVETS to entrepreneurship. The result showed there is a positive relationship between these two variables. The data revealed the more students are exposed to entrepreneurial training the more they will be inclined to pursue entrepreneurship paths. The study showed an absence of entrepreneurship education, there seems to be little focus and attention being placed on entrepreneurial training within PSTVETI. Hurdles and resources stood as two foes that impacted on the positive outlook of PSTVETI within T\&T. These areas will be discussed in detail below. The contribution put forward by the authors provides a platform that will add to the existing body of knowledge to the fields of TVET and entrepreneurship education. Additionally, the contribution of this paper postulates scholarly insights and offers original work, that offers pivotal ideas within the fields of TVET and entrepreneurship education.

Exposure. $\mathrm{H}_{1}$ : A relationship exists between exposing students to entrepreneurial training and students' attraction towards entrepreneurship endeavours

$\mathrm{H}_{0}$ : No relationship exists between exposing students to entrepreneurial training and students' attraction towards entrepreneurship endeavours

Exposing students to entrepreneurship is something worthwhile. This study found a significant relationship between exposing students to entrepreneurial education training and students' entrepreneurship endeavours. (rho $=0.132, N=439$, $p=0.006$, two-tailed). This study showed a positive relationship between students' entrepreneurship education endeavours and their exposure to entrepreneurial education training. Thus, the hypothesis $\mathrm{H}_{1}$ was proven and the alternative $\mathrm{H}_{0}$ must be rejected.

Additionally, the correlation between exposure to entrepreneurship education training and students' entrepreneurship endeavours was significant, thus highlighting the significance of providing students with entrepreneurial education. Not to mention, this speaks to the fact that entrepreneurship education coupled with TVET training is more likely to produce skills-based entrepreneurs. From the survey data, when students were asked if they will be going into business on their own after leaving school, $78 \%$ said yes. This is a high percentage of persons wanting to pursue entrepreneurship, suggesting that the entrepreneurial spirit is alive within the research population and given the enough exposure to entrepreneurship education, the number of TVET graduates pursuing entrepreneurial pathways can be increased. This in part answers the overall research question that under pins this research. An interesting study done by Gerba (2012) found that students that experienced entrepreneurship education are more inclined to have better entrepreneurial aspirations as compared to students who were not exposed to entrepreneurship courses. This is a profound example of how entrepreneurship can shape and provide a platform for TVET students' development.

Another point endorsed by Liñán et al. (2011) stated that greater knowledge about entrepreneurship education can result in students having more convincing views on entrepreneurship. The points articulated by the authors justified the researcher's position and the findings from the research, which states that exposing TVET students to entrepreneurship education can propel students to become entrepreneurs. It endorses the correlation between students' interest to pursue entrepreneurship and exposing students to entrepreneurship education. Exposing students to entrepreneurship education should be a constant endeavour and going forward, TVET institutions within T\&T should consider these findings and put them into effect. A study done by Wang and Verzat (2011) showed that when students are exposed to training in management and entrepreneurial lines they have stronger grit in pursuing entrepreneurship when compared to students that studied only engineering.

An absence of entrepreneurship training. RQ1: What is the present environment involving entrepreneurship education practices at TVET institutions?

RQ2: How does entrepreneurship education or the lack thereof affect students pursuing entrepreneurial paths?

RQ3: How is the current curriculum of TVET skills training equipping students to prepare for entrepreneurship?

The focus of the study was to understand the intricacies associated with entrepreneurship education within TVET institutions however, there is an apparent absence of entrepreneurship training within the four PSTVETI in T\&T. The research questions above sort to determine the present environment relating to practices surrounding entrepreneurship education,, the lack of entrepreneurial education and the current curriculum that can prepare students within vocational lines for business ownership. The study unearthed there was limited and inadequate entrepreneurial training. According to Haolader (2015), combining technical subjects with entrepreneurship courses can provide a stimulus in decreasing unemployment by creating entrepreneurship opportunities. These revelations justify the researchers' position on the value and importance of exposing TVET students to entrepreneurship education. According to Lackeus (2015), the most significant principle of entrepreneurship education is to cultivate some entrepreneurial proficiencies. These characteristics are missing from the institutions' curricula. Entrepreneurship education has to be taught within the curricula to see T\&T reap the benefits entrepreneurship brings. An interesting point was articulated by Basu (2014), saying that the influence of entrepreneurial training can bring about a healthy economy. This provides a useful and pertinent point on the value and significance of entrepreneurship education within TVET institutions' curricula. The researchers ventured to investigate the entrepreneurship education practices, the current climate involving entrepreneurial training and the existing TVET curricula involving entrepreneurial training within TVET institutions, however, the factors emanated from the data showed students were not given the opportunities to pursue an entrepreneurial path, nor are visible signs of entrepreneurship within the curricula of the PSTVETI. There does not seem to be any adoption of an entrepreneurial philosophy within the four PSTVETI. Consequently, the conclusion can be made there is an absence of an entrepreneurial training within the four PSTVETI.

The climate of PSTVETI. RQ1: What is the present environment involving entrepreneurship education practices at TVET institutions?

RQ2: How does entrepreneurship education or the lack thereof affect students pursuing entrepreneurial paths?

The study attempted to answer the research questions above. The data provided insight related to the research questions above. Based on the revelations from the qualitative data there were many difficulties presented, that impacted the schools' ability to allow students to pursue an entrepreneurial path and the present 
environment is rather challenging to envision entrepreneurship practices taking place. Also, the present climate within PSTVETI is complex and requires intervention. The researchers ventured to investigate factors that influence the adoption of entrepreneurial paths of students pursuing TVET programmes. The focus was to understand the intricacies associated with entrepreneurship education within TVET institutions. Therefore, embracing a research philosophy allowed the writers to scrutinise the context in which the events were taking place involving entrepreneurship education. Based on the data below, many hurdles impacted the institutions' ability to implement entrepreneurship education. Consequently, the conclusion can be made there was no adoption of entrepreneurial paths within TVET institutions. Below provides data that speaks to the challenges impacting TVET institutions and highlights why adopting entrepreneurial approaches is non-evident.

Attrition and the quality of trainees were two major problems mentioned by many educators from various institutions.

Educator's response: "So then you have a high failure rate and the fact you will have a high attrition rate as well because people drop out because they just can't cope so it's a whole chain system in alignment with that."

Educator's response: "One of the things is attrition, attrition sometimes is very high and it occurs at the beginning of the cycle and in-between as well, so that is one of the challenges."

One of the leading administrators from the TVET institutions shared a key point on attrition. According to Raghugbar (2016), the MIC-IT programmes carry a $20-25 \%$ attrition rate yearly, a statistic shared by Professor Imbert, Chairman of MIC-IT. This is a large number of persons that withdraw from the programme each year. The institution must put measures in place to mitigate the challenges that confront them. There are many reasons why students drop out, some for social reasons, others for their inability to cope with the curriculum. The institutions, therefore, must put systems in place that can confront and treat these difficulties.

The quality of the trainees was a significant challenge as well. Many of the trainees at the various institutions come from lowincome areas. In addition to this, the education background of students is insufficient to handle even the rigors of the institutions' introductory curriculum. Please see educator statements below:

Educator's response: "Some of the candidates that enter the system they're lacking and I would say that it is a chain effect because it lacking not really from coming here they are lacking from the Secondary School system so the Secondary School system plays a part in terms of TVET because the clientele that we would get coming from the Secondary School system".

Another problem that TVET institutions face is a lack of adequate training, both theory and practical. There was an absence of industrial training within the ranks of TVET institutions. Also, the quality of teaching due to the lack of standardisation was an apparent issue. Many of the educators at the institutions had opinions on these issues.

Educator's response: "I advise my students when they have finished the program to at least spend a year or two getting some hands-on experience. We have equipment but we don't have all the equipment and when they go to a company they are exposed to a wide variety of equipment."

A profound position articulated by Dundar et al. (2014) states that Sri Lanka, in seeking to be a regional hub in strategic capacities, sought to develop a practical skills development structure that would aid in their diversification strategy and enhance their labour capabilities. Sri Lankan authorities also hoped that a skills development programme would improve efficiency and competitiveness. This will give their nation a great degree of flexibility to compete globally and diminish their poverty levels. Sri Lanka's justifications for an effective and efficient TVET system can also work for T\&T. TVET institutions, and their administrators must see the need to provide direction and guidance that will enable TVET to thrive in a healthy and conducive environment.

Judging from the data both research questions were answered, but it also allows the reader to understand the fundamental difficulties that exist within the PSTVETI. The climate within PSTVETI is rather challenged and requires assistance from a strategic and political level.

Present entrepreneurship framework. RQ4: How can incorporating an entrepreneurship education model improve TVET in $\mathrm{T} \& \mathrm{~T}$ ?

Research question four attempted to enquire about the incorporation of an education model to improve TVET within T\&T. The data showed there was no such thing as an entrepreneurial model for entrepreneurial training emerging from within the four PSTVETI. However, the writers intend to put forward some insights on how this can be possible and answer the fourth research question. One of T\&T's scholars within academia stated there is no real visible entrepreneurship education framework for T\&T (Ramkissoon-Babwah, 2012). This research explored the possibility of an education framework that allowed the researchers to critically review the entrepreneurial component of the curricula of the four (4) PSTVETI; these TVET institutions fall under the purview of the tertiary education division of the Ministry of Education of T\&T. This was executed by conducting a content analysis and ascertaining the status of entrepreneurship education at the four TVET institutions. According to educators, PSTVETI 1 and 2 do not have any entrepreneurship education except for life skills, which carry just a minute aspect of entrepreneurship education. On the contrary, PSTVETI 3 and 4 have entrepreneurship education as an option in their curriculum. PSTVETI 3 and 4 and execute entrepreneurship education by teaching six (6) main subjects which include: Accounting, Customer Care, Economics, Entrepreneurship, Marketing and Management. The courses at PSTVETI 3 range from 135-270 contact hours depending on the programme of study. PSTVETI 3 have four main programmes at the Associate degree level, which cover the above subjects in entrepreneurship education; the courses include Culinary Arts, Food and Beverage, Hospitality Studies and Tourism Studies. PSTVETI 4 course entitled "Micro Entrepreneurship", which is a certificate programme covers $144 \mathrm{~h}$. PSTVETI 4 programme on the hand, cover only four out of the six subjects mentioned above in their curriculum, Customer Care and Economics are not covered, therefore comprising a total of 118 contact hours.

The writers' intention is to reveal that incorporating entrepreneurship in a structured manner provides the right platform for advancing the entrepreneurship agenda. Comparing what was expressed above regarding the four (4) PSTVETI a comparison was made with local (PSTVETI) and international TVET programmes. In Haolader's (2015) research, it was revealed in Bangladesh TVET students incorporated business skills in their four-year diploma engineering programme in Electronics Technology, which include the following subjects: organisation of business, communication, bookkeeping and accounting, industrial management, environmental management, and entrepreneurship. In Serbia, research highlighted an institution that offers TVET programmes, married business training in their Pharmacy, Chemistry and Environmental programmes. Students were exposed to the following courses:: budgeting, law, marketing, management and leadership research sales, quality control. 
This training incorporated practical hands on field work (McCallum, 2019). According to Ibrahim et al. (2015), Malaysian students are exposed to entrepreneurial training at the National Youth Skills Institute (NYSI) no matter what programme they pursue. They cover the following topics: entrepreneurship, entrepreneurial motivation, business establishment, business records and documents, basic accounting, marketing, and business communication. Comparing the three countries, Bangladesh, Serbia, and Malaysia to T\&T, one can see a contrast in the entrepreneurship curricula. There is some focus on entrepreneurship education at PSTVETI 3 and there is no emphasis on entrepreneurship education at PSTVETI 1 and 2. Given the pivotal role entrepreneurship plays in contributing to any society's human capital development, there should be consideration moving forward to incorporate these principles into the curricula of all TVET institutions that are part of this study and to the wider society of T\&T.

\section{Research gaps}

There is also limited research done on entrepreneurship education within Small Island Developing States (SIDS), not to mention that places emphasis on TVET. Thus, this study provides originality and contribution to the field of TVET and entrepreneurship education, especially as it relates to SIDS. In T\&T there is no real skills policy. There is a policy relating to tertiary education but there is little focus of skills training. When reviewing T\&T National Youth Policy (NYP) it does not address TVET. Another point, to note the present NYP goes far back as 1998. Hence, T\&T NYP is not to up to date and current. Both points relating to TVET policy and a relevant NYP speak to some challenges relating to these areas. Also, research relating to entrepreneurship education and TVET is limited within T\&T. There is not a great deal of extensive research that would comment or articulate policy and matters relating to T\&T. A leading scholar at T\&T's leading university stated that there is a dearth of research within the Caribbean that focuses on entrepreneurial education (Ramkissoon-Babwah, 2012).

\section{Conclusion}

Attention was placed on four (4) PSTVETI within T\&T. Many ideas unearthed several hurdles facing the institutions. TVET institutions have a key role to play in ensuring human capital is realised. On the other hand entrepreneurship education and TVET are two instrumental vehicles that can be used to the advancement of T\&T. The study portrayed the importance of TVET and role in can play in sustainable development for T\&T. Entrepreneurship education was highlighted as a significant driver for the nation's development. The Theoretical model, on The Theory of Planned Behaviour, provided some context on approaching the notion of entrepreneurial intentions. The model captured authors views on how this theory can be incorporated within the study. The null hypothesis was accepted, thus providing the notion that more exposure to entrepreneurial training increases students interest in entrepreneurship. The data collection saw the use of three data methods; survey, interviews, and content analysis, which serve as a pivotal measure in gathering dependable data throughout the study. The data were analysed embracing quantitative and qualitative techniques. This allowed the researchers to use: Logistic Regression, Spearman Correlation, Content Analysis and Thematic Analysis. Three main themes emerge from research findings that included: Exposure to entrepreneurship education, an absence of entrepreneurial training and the climate of PSTVETI. Lastly, the researcher put forward an entrepreneurial model, which can be incorporated with the training of vocational institutions within T\&T.

\section{Recommendations}

TVET institutions should have an entrepreneurial education programme strategy built into their curriculum. This strategy can be done by incorporating entrepreneurship education from within their various levels of their TVET training. For example if TVET institutions have a level 1-7 programme, entrepreneurship education can be incorporated throughout these levels. They can offer a course called Entrepreneurship Educational Fundamentals (EEF) level 1 and 2 can be taught to exposed students to business and management training that will prepare them for the world of entrepreneurship. For instance, students starting off at level 1-4 would be taught EEF 1, which they will be exposed to entrepreneurship courses geared at: basic law involving their various vocational areas, basic financial management, self-esteem and personal development and the entrepreneurial identity. The students can be exposed to different topics/units at each level in levels $1-4$. When students commenced EEF 2 they will be taught advance courses in entrepreneurship education. The intention here is to offer training at a higher level of business expertise, thus ensuring students can manage an enterprise and carry out practical scenarios in managing a micro business. Another part of this strategy is no matter what level, students commence their TVET studies, they should be timetabled entrepreneurship education 1 and 2 as mandatory courses. This can be done by timetabling EEF and 1 and 2 that would be factored in at all levels. The timetable should be progressive, hence students would cover EEF 1 courses first and then cover EEF 2 courses afterwards, which will be done alongside their TVET training. However, entrepreneurship education should not only commence at the PSTVETI but even from early as primary school. This will create an entrepreneurial culture from early. This idea was endorsed by Ramkissoon-Babwah (2012) that articulated the view that entrepreneurship education should penetrate the three levels of T\&T's education system, which includes primary, secondary and tertiary. Thus contributing to the narrative of early entrepreneurship education that will lead to a country's unending development. Lastly, the model put forward provides an opportunity that will contribute further to the fields of TVET and entrepreneurship thus providing originality within the respective fields of study.

\section{Data availability}

The datasets generated during and/or analysed during the current study are not publicly available for reasons of privacy. The data are therefore not available for public sharing, but they can be made available from the corresponding author on reasonable request.

Received: 20 December 2020; Accepted: 31 August 2021; Published online: 06 October 2021

\section{References}

Abioye R (2020) Exploring the impact of entrepreneurship education program on current graduate entrepreneurs [Doctoral thesis, Walden University]. https:// scholarworks.waldenu.edu/cgi/viewcontent.cgi? article $=9705 \&$ context $=$ dissertations

Ajzen I (1991) The theory of planned behavior. Organ Behav Hum Decis Process 50(2):179-211. https://doi.org/10.1016/0749-5978(91)90020-T

Aring M (2011, April). Promising youth development strategies. Education. Education Development Center, Inc

Basu R (2014) Entrepreneurship education in India: A Critical Assessment and a Proposed Framework. Technol Innov Manage Rev 4:5-10. https://doi.org/ 10.22215/timreview/817

Bowen GA (2009) Document analysis as a qualitative research method. Qual Res J 9(2):27-40. https://doi.org/10.3316/QRJ0902027

Boxhill I, Chambers C, Wint E (1997) Introduction to social research. Kingston: Canoe Press University of the West Indies 
Brannen J (2005) Mixed methods research: a discussion paper. http:// eprints.ncrm.ac.uk/89/1/MethodsReviewPaperNCRM-005.pdf

Brew EM, Dadzie J (2016) Partnership between TVET Training Institutions and Industry: A Survey of Industrial Experience of Academic Staff of Accra Polytechnic Mathematical theory and modeling 6:131-135

Bryman A (2012) Social research methods. 4th. New York: Oxford University Press Inc

Dhaliwal A (2016) Role of entrepreneurship in economic development. Int J Scient Res manage 4.06:4262-4269

Dundar H, Millot B, Savchenko Y, Aturupane H, Piyasiri AT (2014) Building the skills for economic growth and competitiveness in Sri Lanka. The World Bank, Washington, D.C, https://openknowledge.worldbank.org/bitstream/ handle/10986/18409/882690PUB0978100Box385205B00PUBLIC0.pdf

Gamede TG (2017) The role of entrepreneurship education in secondary schools at further education and training phase. Acad Entrepreneurship J 23(2):2017

Gerba DT (2012) Impact of entrepreneurship education on entrepreneurial intentions of business and engineering students in Ethiopia. Afr J Econ Manag Stud 3.2:258-277

Haolader F (2015) Entrepreneurship education in TVET for small and medium enterprise development: a case study in Bangladesh. Bangladesh Educ J 14:27-44

Ibrahim WN, Bakar AR, Asimiran S, Mohamed S, Zakaria NS (2015) Impact of entrepreneurship education on the entrepreneurial. 8. Malaysia: Canadian Center of Science and Education. https://doi.org/10.5539/ies.v8n12p141

Liñán F, Urbano D, Guerrero M (2011) Regional variations in entrepreneurial cognitions: Start-up intentions of university students in Spain. Entrepreneurship Reg Dev 23:187-215. https://doi.org/10.1080/08985620903233929

Mack A, White D, Senghor O (2019) An insight into entrepreneurship education practices in Technical and Vocational Education and Training institutions. J Glob. Entrepreneurship Res. Retrieved from: https://doi.org/10.1186/s40497019-0169-z

Lackeus M (2015) Entrepreneurship in education What, when why and how. Entrepreneurship SME's tourism and local development, Paris

Liñán F, Santos FJ (2007) Does social capital affect entrepreneurial intentions? Int Adv Econ Res 13:443-453. https://doi.org/10.1007/s11294-007-9109-8

Mack A, White D (2019) Challenges affecting technical vocational education and training in Trinidad \& Tobago: stakeholders' perspectives. J Tech Educ Train. 11(3). Retrieved from https://publisher.uthm.edu.my/ojs/index.php/JTET/ article/view/4080

McCallum E (2019) Entrepreneurial learning in TVET Discussion paper. https:// unevoc.unesco.org/pub/entrepreneurial_learning_discussion_paper1.pdf

Patton MQ (2015) Qualitative research \& evaluation methods: integrating theory and practice, 4th edn. Sage, Thousand Oaks, CA

Raghugbar C Prof Imbert. (2016, July 23) High drop-out, failure at MIC. Trinidad and Tobago Guardian Newspaper

Ramkissoon-Babwah N (2012) An entrepreneurship education model for Trinidad and Tobago. J Emerg Trend Educ Res Policy Stud 2141-6990:307-311

Ryan GW, Bernard HR (2003) Techniques to identify themes. Field Methods

Saunders M, Lewis P, Thornhill A (2003) Research methods for business students. 3rd. Pearson Education Limited, England
Saunders B, Sim J, Kingstone T, Baker S, Waterfield J, Bartlam B, Burroughs H, Jinks C (2018) Saturation in qualitative research: exploring its conceptualization and operationalization. Qual Quant 52(4):1893-1907. https:// doi.org/10.1007/s11135-017-0574-8

Seng LS (2010) Case study on national policies Linking TVET with economic expansion: lessons from Singapore

Singh A, Masuku M (2014) Sampling techniques \& determination of sample. Int J Econ Commerce Manag II.11, http://ijecm.co.uk/wp-content/uploads/2014/ 11/21131.pdf

Tambunan T (2019) Recent evidence of the development of micro, small and medium enterprises in Indonesia. J Global Entrepreneurship Res

Tikly L (2013) Chapter 1: Reconceptualizing TVET and development: a human capability and social justice approach

Wang Y, Verzat C (2011) Generalist or specific studies for engineering entrepreneurs? Comparison of French engineering students' trajectories in two different curricula. J Small Bus Enterp Dev, 18(2). https://doi.org/10.1108/ 14626001111127124

\section{Funding}

Funding was not provided for the article from any funding body or organisation.

\section{Competing interests}

The authors declare no competing interests.

\section{Additional information}

Correspondence and requests for materials should be addressed to Abede Jawara Mack.

Reprints and permission information is available at http://www.nature.com/reprints

Publisher's note Springer Nature remains neutral with regard to jurisdictional claims in published maps and institutional affiliations.

Open Access This article is licensed under a Creative Commons Attribution 4.0 International License, which permits use, sharing, adaptation, distribution and reproduction in any medium or format, as long as you give appropriate credit to the original author(s) and the source, provide a link to the Creative Commons license, and indicate if changes were made. The images or other third party material in this article are included in the article's Creative Commons license, unless indicated otherwise in a credit line to the material. If material is not included in the article's Creative Commons license and your intended use is not permitted by statutory regulation or exceeds the permitted use, you will need to obtain permission directly from the copyright holder. To view a copy of this license, visit http://creativecommons.org/ licenses/by/4.0/.

(C) The Author(s) 2021 